\title{
Isolation of Plant Hormone (Indole-3-Acetic Acid - IAA) Producing Rhizobacteria and Study on their Effects on Maize Seedling
}

\author{
Khin Mya Lwin ${ }^{1, \mathrm{a}}$, Moe Moe Myint ${ }^{1, \mathrm{~b}}$, Tar Tar ${ }^{2, \mathrm{c}}$, and Wai Zin Moe Aung ${ }^{2, \mathrm{~d}}$ \\ 1 Department of Biotechnology, Mandalay Technological University, Myanmar \\ 2 Department of Biotechnology, Technological University Kyaukse, Myanmar \\ E-mail: akhinzarni@gmail.com (Corresponding Author), bmoemoem@gmail.com, ckokotartar@gmail.com, \\ dwaizinmoeaung@gmail.com
}

\begin{abstract}
Mandalay region, Myanmar and some of their biochemical characteristics were studied. Among them, 4 isolates belonged to Bacillus spp. and another 5 strains were recognized as Serratia spp. All 18 isolates were screened for indole-3-acetic acid (IAA) production and quantitative determination of IAA was done for all strains by UV-Vis spectrophotometer with 2 days interval during 10 days incubation. All isolates had different optimum IAA production periods and strain R1 was the best IAA producer strain with $121.1 \mathrm{ppm}$. It was observed that Bacillus spp. produced IAA ranging from $53.1 \mathrm{ppm}$ to $71.1 \mathrm{ppm}$ optimally and Serratia spp. were regarded as poor IAA producers. Among these 18 strains, the best four IAA producers (R1, R3, R5, R8) were selected for further study on maize plant and their activities of nitrogen fixation were also detected by plate screening method. Seed germination rate was studied with eight types of treatment and the treatments with isolates did not show significant effects on seed germination rate. At $20^{\text {th }}$ day after sowing, dry root weight and fresh root weight, root length, number of adventitious roots, dry shoot weight and fresh shoot weight and shoot height were analyzed. In pot trial experiment, treatment R1 significantly increased the fresh shoot weight, shoot height and dry shoot weight whereas treatment R3 significantly increased fresh root weight, root length, dry root weight and number of adventitious roots and all treatments with bacterial isolates showed plant growth promotion than the control systems.
\end{abstract}

Keywords: Plant hormone, indole-3-acetic acid, rhizobacteria, Bacillus spp., Serratia spp., maize.

ENGINEERING JOURNAL Volume 16 Issue 5

Received 20 February 2012

Accepted 27 May 2012

Published 1 October 2012

Online at http://www.engj.org/

DOI:10.4186/ej.2012.16.5.137 


\section{Introduction}

In order to meet the challenges of providing food to the ever increasing population of Myanmar, there is an urgent need to boost crop yield. As the rate of population increased, there is also an excessive increase in the usage of chemical fertilizers and pesticides for various purposes. Although achieving the satisfactory results by the application of chemical fertilizers and pesticides, the disadvantages of chemical fertilizers and pesticides are now threatening the agricultural processes, such as pollution of large water resources, destruction of microorganisms, acidity of the soil and reduction in soil fertility.

In the recent years, scientists have diverted their attention towards exploring the potential of beneficial microbes and the use of plant growth promoting rhizobacteria (PGPR) for sustainable agriculture has increased tremendously in various parts of the world. Plant growth promoting rhizobacteria (PGPR) are group of bacteria that actively colonize plant roots region and increase plant growth and yield [1]. Various species of bacteria like Pseudomonas, Azospirillum, Azotobacter, Klebsiella, Enterobacter, Alcaligenes, Arthrobacter, Burkholderia, Bacillus and Serratia have been reported to enhance the plant growth [2-5]. PGPR enhance plant growth either by direct or indirect mechanisms. The direct growth promoting mechanisms involve nitrogen fixation, solubilization of minerals, production of phytohormones and the indirect approach occurs when PGPR lessen or prevent the deleterious effects of plant pathogens on plants [6].

Plant hormones regulate or influence a range of cellular and physiological process, such as cell division, cell enlargement, bud dormancy, flowering, fruit ripening, seed dormancy, seed germination and leaf abscission. Auxin, one of the plant hormones, stimulates differentiation of phloem and xylem, root initiation on stem cutting, and also the development of branch roots. Auxin mediates the tropism (bending), response to gravity and light [7]. Indole -3-acetic acid (IAA) is the common natural auxin that shows all auxin doing actions and extensively affects plant's physiology. Colorimetric method is the simplest method and has long been employed for the detection of indole-3-acetic acid (IAA) produced by plants and microorganisms [8] and this hormone is detected in $80 \%$ of bacteria isolated from the rhizosphere.

The objectives of this research are to study the IAA hormone production of PGPR and to determine effect of IAA hormone on seed germination and plant growth promotion of maize.

\section{Experimental}

\subsection{Isolation of Rhizobacteria from Various Sources}

For the isolation of rhizobacteria, samples were collected from rhizospheric soil of various plants such as paddy, tomato, chickpea, and carrot in Mandalay region and stored in polyethylene bag for transport to the laboratory. One gram of soil sample was placed in a sterile test tube and mixed with $10 \mathrm{ml}$ of $0.9 \% \mathrm{NaCl}$ solution. It was vigorously shaken for a few minutes. Then, sample was cultured on glucose nitrogen free mineral medium (G-NFMM), Bacillus medium, nutrient agar and incubated at $30^{\circ} \mathrm{C} .18$ bacterial colonies with different growth characteristics were isolated and purified by further streaking on these media and pure cultures were used for further experiments.

\subsection{Biochemical Characterization of Isolated Rhizobacteria}

All isolates were characterized by Gram reaction, catalase, citrate utilization, urease, indole, methyl red, voges-proskauer, gelatin agar test, starch hydrolysis and their motility were also studied.

\subsection{Quantitative Determination of IAA Production from Rhizobacteria}

4 Bacillus isolates (B1, B2, B3, B4) and 5 strains of Serratia spp. (S1, S2, S3, S4, S5) were inoculated in the nutrient broth and the rest 9 rhizobacteria (R1, R2, R3, R4, R5, R6, R7, R8, R9) were incubated in GNFMM at $30^{\circ} \mathrm{C}$ for 24 hours. $2 \mathrm{ml}$ of inoculum was added to the $20 \mathrm{ml}$ liquid medium containing $0.5 \mathrm{~g} / \mathrm{L}$ of tryptophan and incubated at $30^{\circ} \mathrm{C}$ about two weeks.

$1 \mathrm{ml}$ of bacterial culture was collected from $20 \mathrm{ml}$ incubating broth from $2^{\text {nd }}$ day up to $10^{\text {th }}$ day with 2 days interval and centrifuged at $6000 \mathrm{rpm}$ for 30 minutes. $1 \mathrm{ml}$ of the supernatant was mixed with 1 drop of orthophosphoric acid and $2 \mathrm{ml}$ of Salkowski's reagent $\left(50 \mathrm{ml}, 35 \%\right.$ perchloric acid and $\left.1 \mathrm{ml}, 0.5 \mathrm{MFeCl}_{3}\right)$. 
Development of a pink color indicated IAA production and the amount of IAA was measured by spectrophotometric method at $530 \mathrm{~nm}[9]$.

\subsection{Screening of Nitrogen-Fixing Activity}

The visual detection of nitrogen-fixing activities of the selected 4 IAA producing strains (R1, R3, R5, R8) were observed by using glucose nitrogen free mineral medium (G-NFMM). Single colony grown on nitrogen free medium was taken and inoculated into G-NFMM containing BTB (bromothymol blue solution). After one week incubation, appearance of blue green color change from green color indicated that the isolate had nitrogen fixing activity.

\subsection{Germination Assay}

To study the effect of IAA on germination rate, 100 seeds of maize (Zea mays L.) were prepared for each treatment. For sterilization, seeds were soaked in $2 \%$ sodium hypochlorite for 3 minutes and then they were washed by sterile distilled water for 5 times. Sterilized seeds were incubated with $50 \mathrm{ml}$ of each treatment at room temperature for 24 hour. Treatment systems were (R1, R3, R5, R8) with R1, R3, R5, R8 strains, C $(\mathrm{C}=\mathrm{R} 1+\mathrm{R} 3+\mathrm{R} 5+\mathrm{R} 8)$ and 3 kinds of control such as water, G-NFM broth with no microbe and ferti- start were also set up. Ferti- start is a commercial rooting product that is widely used in horticulture in Myanmar and it is used as positive control for this experiment. After 24 hours incubation, the soaked seeds were placed in sterilized cup containing wet cloth and they were incubated at room temperature for 5 day to calculate the percent germination.

\subsection{Pot Trial Experiment for Maize Seedling}

Maize (Zea mays L.) was used as plant model in this experiment. Maize seeds were soaked in 2\% sodium hypochlorite for 3 minutes and the seeds were washed with sterile water about 5 times. Sterilized seeds were incubated with $50 \mathrm{ml}$ of each treatment at room temperature for 24 hour. Treatments were (R1, R3, R5, R8) with R1, R3, R5, R8 strains, C (C=R1+R3+R5+R8) and 3 kinds of control such as water, G-NFM broth with no microbe and ferti- start were also set up. After 24 hours incubation, the soaked 3 seeds (in the depth of $2 \mathrm{~cm}$ ) were sowed in a plastic bag filling with equal amount of soil and five replicates were set for each treatment. To supply the need of IAA for plant, $100 \mathrm{ml}$ of each treatment was added to five bags in equal amount after five day planting. At $20^{\text {th }}$ day, the maize plants were harvested separately according to the treatment. The effects of different treatments were observed and there were the important plant indexes such as root length, fresh root weight and dry root weight, shoot height, fresh shoot weight and dry shoot weight and the number of adventitious roots.

\section{Results and Discussions}

\subsection{Morphological and Biochemical Characterization of Rhizobacteria}

18 rhizobacteria were isolated from various rhizospheric soils in Mandalay and they were identified by some morphological and biochemical characteristics. Among them, 4 isolates (B1, B2, B3, B4) belonged to Bacillus spp. and another 5 strains (S1, S2, S3, S4, S5) were recognized as Serratia spp.

\subsection{Examination of Optimum IAA Production Period for Isolated Strains by UV-Vis Spectrophotometer}

The standard IAA calibration curve was set up by determining the prepared different concentrations of authentic IAA at $530 \mathrm{~nm}$ with UV spectrophotometer. As shown in Table 3, 4 and 5, the optimum IAA productions of all Serratia spp. were found at $8^{\text {th }}$ day incubation while the rest rhizobacteria were at $4^{\text {th }}, 6^{\text {th }}$ and $8^{\text {th }}$ incubation. Among all isolates, strain R1 was the best IAA producer with $121.1 \mathrm{ppm}$ and Serratia spp. produced only small amount of IAA. The amounts of IAA produced by isolates declined slightly day by day after they reached their peak because of its transformation to IAA derivatives. From this result, four of the best IAA producers (R1, R3, R5, and R8) were selected for further study. 
Table 1. Some biochemical characteristics of isolated bacteria.

\begin{tabular}{|c|c|c|c|c|c|c|c|c|c|}
\hline Tests & B1 & B2 & B3 & B4 & $\mathrm{S} 1$ & $\mathbf{S} 2$ & S3 & S4 & S5 \\
\hline Gram stain & + & + & + & + & - & - & - & - & - \\
\hline Catalase & + & + & + & + & + & + & + & + & + \\
\hline Starch hydrolysis & + & + & + & + & - & - & - & - & - \\
\hline Citrate utilization & + & + & - & + & + & + & + & + & + \\
\hline Urease & - & - & - & - & + & + & + & + & + \\
\hline Gelatin test & + & + & + & + & + & + & + & + & + \\
\hline Indole & - & - & - & - & - & - & - & - & - \\
\hline Methyl red & - & - & - & + & - & - & - & - & - \\
\hline Voges-Proskauer & + & - & - & + & + & + & + & + & + \\
\hline Motility & + & - & - & - & + & + & + & + & + \\
\hline
\end{tabular}

Table 2. Some biochemical characteristics of isolated bacteria.

\begin{tabular}{|c|c|c|c|c|c|c|c|c|c|}
\hline Str & & & & & & & & & \\
\hline Tests & $\mathbf{R} 1$ & $\mathbf{R} 2$ & R3 & R4 & R5 & R6 & R7 & R8 & R9 \\
\hline Gram stain & - & - & - & - & - & - & - & - & - \\
\hline Catalase & + & + & + & + & + & + & + & + & + \\
\hline Starch hydrolysis & + & - & + & - & + & - & - & - & - \\
\hline Citrate utilization & + & + & + & + & - & - & + & - & + \\
\hline Urease & - & - & - & + & - & + & + & + & - \\
\hline Gelatin test & - & - & - & - & - & - & - & + & - \\
\hline Indole & - & - & - & - & - & - & - & - & - \\
\hline Methyl red & - & - & - & - & + & - & - & - & - \\
\hline Voges-Proskauer & - & + & - & + & + & - & + & - & + \\
\hline Motility & + & + & + & - & + & - & - & - & + \\
\hline
\end{tabular}

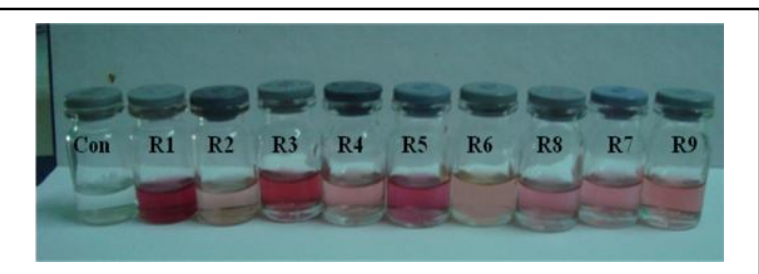

Fig. 1. IAA production by nine rhizobacteria. 
Table 3. IAA production by Bacillus spp.

\begin{tabular}{|c|c|c|c|c|c|}
\hline Day & Day 2 & Day 4 & Day 6 & Day 8 & Day 10 \\
\hline & \multicolumn{5}{|c|}{ IAA Concentration (ppm) } \\
\hline B1 & 33.60 & 62.80 & 56.30 & 48.70 & 46.60 \\
\hline B2 & 34.90 & 71. & 57. & 53. & 52.10 \\
\hline B3 & 31.90 & 45.50 & 66.20 & 61.10 & 56.30 \\
\hline B4 & 28.10 & 29.30 & 48.30 & 53.10 & 50.60 \\
\hline
\end{tabular}

Table 4. IAA production by Serratia spp.

\begin{tabular}{|c|c|c|c|c|c|}
\hline Day (s) & Day 2 & Day 4 & Day 6 & Day 8 & Day 10 \\
\hline Isolates & \multicolumn{5}{|c|}{ IAA Concentration (ppm) } \\
\hline S1 & 3.14 & 4.69 & 5.07 & 13.36 & 12.40 \\
\hline S2 & 5.90 & 8.57 & 10.05 & 16.41 & 13.64 \\
\hline S3 & 3.12 & 3.26 & 8.74 & 9.71 & 6.31 \\
\hline S4 & 2.50 & 4.31 & 6.21 & 20.05 & 17.67 \\
\hline S5 & 3.21 & 10.64 & 13.62 & 13.67 & 5.57 \\
\hline
\end{tabular}

Table 5. IAA production by nine rhizobacteria.

\begin{tabular}{cccccc}
\hline \multirow{5}{*}{ Day $(\mathrm{s})$} & Day 2 & Day 4 & Day 6 & Day 8 & Day 10 \\
\cline { 2 - 6 } Isolates & \multicolumn{5}{c}{ IAA Concentration (ppm) } \\
\hline R1 & 34.7 & 89.0 & 121.1 & 112.8 & 97.2 \\
R2 & 19.5 & 22.6 & 21.5 & 35.7 & 21.2 \\
R3 & 35.7 & 103.5 & 107.2 & 87.9 & 52.6 \\
R4 & 30.1 & 32.2 & 34.5 & 30.6 & 21.1 \\
R5 & 32.3 & 53.0 & 92.6 & 52.9 & 43.3 \\
R6 & 15.4 & 66.9 & 22.5 & 19.7 & 17.4 \\
R7 & 12.4 & 31.7 & 52.4 & 36.1 & 28.4 \\
R8 & 23.9 & 71.6 & 47.8 & 17.9 & 15.0 \\
R9 & 16.6 & 33.1 & 37.2 & 34.1 & 32.0 \\
\hline
\end{tabular}

\subsection{Screening of Nitrogen Fixing Activity of the Best Four IAA Producer Strains}

The best four IAA producing strains were also screened for nitrogen fixing activity on G-NFM medium with BTB which was used as indicator to study the release of ammonium in the culture as shown in Fig. 2. At glucose $0.5 \%$, all four strains were observed to fix nitrogen by changing the dark green color to blue green color distinctly, while the other glucose concentrations $(0.3 \%$ and $0.7 \%)$ showed no distinct or poor color changes and these glucose concentrations probably inhibited nitrogenase synthesis. 


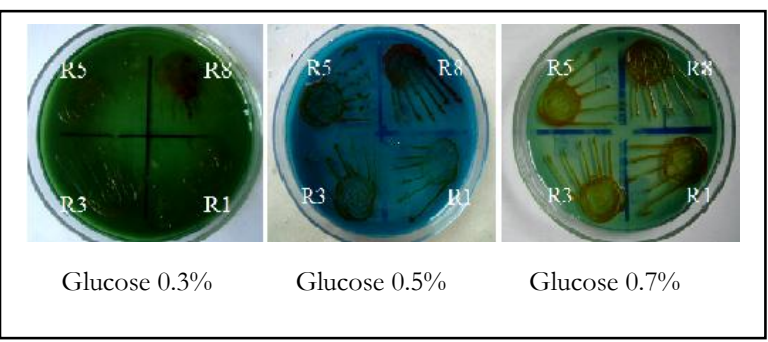

Fig. 2. Screening of nitrogen-fixing activity.

\subsection{Germination Rate of Maize Seed by the Best IAA Producer Strains}

In this study, the most treatments did not show significant positive effect on seed germination rate while water and R8 treatments showed $99 \%$ germination. According to this experiment, it is necessary to investigate the suitable hormone concentration depending on the different crops to achieve the desire rate.

Table 6. Germination rate of maize seeds with various treatments.

\begin{tabular}{lr}
\hline Treatments & $\begin{array}{r}\text { Germination } \\
\text { Percent }\end{array}$ \\
\hline R1 & $97 \%$ \\
R3 & $96 \%$ \\
R5 & $96 \%$ \\
R8 & $99 \%$ \\
C (R1+R3+R5+R8) & $92 \%$ \\
G-NFM Broth (no microbe) & $95 \%$ \\
Water & $99 \%$ \\
Ferti-start & $97 \%$ \\
\hline
\end{tabular}

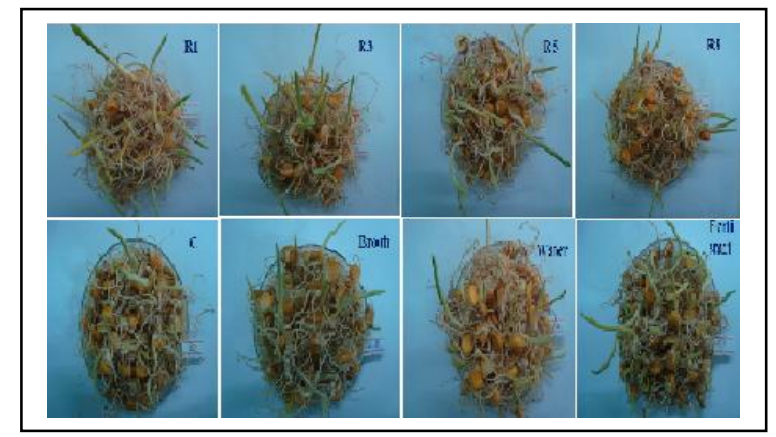

Fig. 3. Germination assay.

\subsection{Effect of the Best IAA Producer Strains on Maize Seedling}

After 20 days of plantation, all of these strains showed significant increase in root and shoot systems than the three controls. R3 strain showed the best result in root length, fresh root weight, number of adventitious roots and dry root weight, whereas R1 strain had the highest shoot height, fresh shoot weight and dry shoot weight. According to this experiment, the best four isolated rhizobacteria were known to exert beneficial effects upon plant growth of maize and they were suitable to use in biofertilizer with IAA producing activities and nitrogen fixation activities. 
Table $7 . \quad$ The effect of the treatments on maize rooting system.

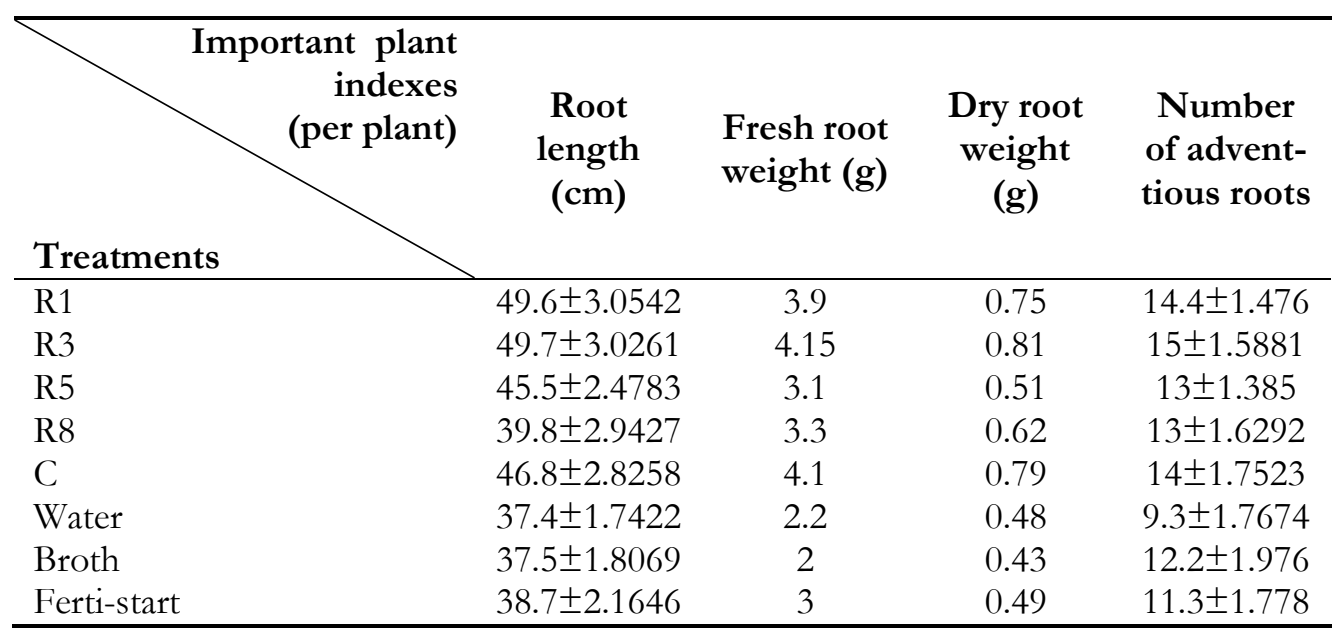

Table 8. The effect of the treatments on maize shooting system.

\begin{tabular}{lccc}
\hline $\begin{array}{c}\text { Important plant } \\
\text { indexes } \\
\text { (per plant) }\end{array}$ & $\begin{array}{c}\text { Shoot height } \\
\mathbf{( c m )}\end{array}$ & $\begin{array}{c}\text { Fresh shoot } \\
\text { weight } \mathbf{( g )}\end{array}$ & $\begin{array}{c}\text { Dry shoot } \\
\text { weight } \mathbf{( g )}\end{array}$ \\
\hline Treatments & $28.7 \pm 2.332$ & 4.2 & 0.65 \\
R3 & $25.8 \pm 1.7766$ & 3.7 & 0.57 \\
R5 & $24.9 \pm 1.6691$ & 3.4 & 0.49 \\
R8 & $24.8 \pm 1.5392$ & 3.2 & 0.5 \\
C & $28.1 \pm 2.1669$ & 4.1 & 0.59 \\
Water & $21 \pm 1.845$ & 2.2 & 0.34 \\
Broth & $20.5 \pm 1.4437$ & 2 & 0.31 \\
Ferti-start & $21.8 \pm 1.5798$ & 3 & 0.38 \\
\hline
\end{tabular}

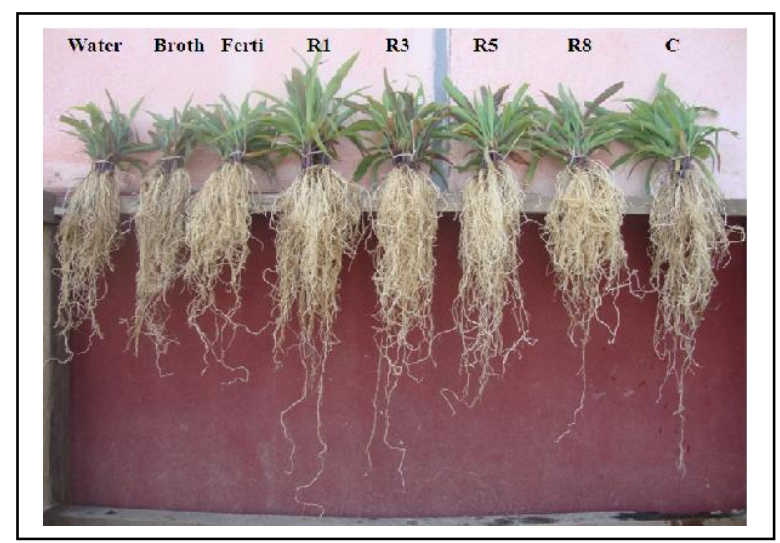

Fig. 4. The effect of the treatments on maize plants.

\section{Conclusion}

In this study, 18 rhizobacteria were isolated from various sources. According to morphological and biochemical characteristics, 4 isolates were recognized as Bacillus spp. while another 5 strains were regarded 
as Serratia spp. All isolated rhizobacteria produced different amounts of IAA and the highest amount of IAA $(121.1 \mathrm{ppm})$ was produced by $\mathrm{R} 1$ at $6^{\text {th }}$ day. The best four IAA producing strains also had the nitrogen fixing activity with $0.5 \%$ glucose in BTB containing G-NFM medium. These strains did not promote seed germination rate significantly although the treatments with desired strains enhanced not only hairy root system but also shoot formation than all controls. Moreover, R3 strain was the best for root formation while R1 isolate distinctly promoted shoot system.

\section{Acknowledgement}

Firstly, I wish to express my thanks to His Excellency Minister, U Aye Myint, Ministry of Science and Technology, for allowing me to research this title. I wish to convey my special thanks to Dr. Mya Mya Oo, Rector of both Yangon Technological University and Mandalay Technological University, for her provision of research facilities. I would like to extend my deep gratitude to my companion Moe Moe Myint, Tar Tar and Wai Zin Moe Aung, for their patience and helping hands.

\section{References}

[1] P. J. Davies, Plant Hormones: Physiology, Biochemistry, and Molecular Biology. Kluwer Academic Publishers, Netherlands, 1995.

[2] R. Pichu, "Free-living bacterial inoculate for enhancing crop productivity," Trends in Biotechnology, vol. 7, pp. 39-44, 1989.

[3] Y. Okon and C. A. Labandera-Gonzalez, "Agronomic applications of Azospirillum," in Improving Plant Productivity with Rhizosphere Bacteria, Australia: Commonwealth Scientific and Industrial Research Organization, 1994.

[4] B. R. Glick, "The enhancement of plant growth by free living bacteria," Canadian Journal of Microbiology, vol. 41, pp. 109-114, 1995.

[5] A. Munees and S. K. Mohammad, "Functional aspect of plant growth promoting rhizobacteria," Insight Microbiology, vol. 1, pp. 39-54, 2001.

[6] M. A. Anjum, M. R. Sajjad, N. Akhtar, M. A. Qureshi, A. Iqbal, A. R. Jami, and M. U. Hasan, "Response of cotton to plant growth promoting rhizobacteria (PGPR) inoculation under different levels of nitrogen," Journal of Agricultural Research, vol. 45, no. 2, pp. 135-143, 2007.

[7] M. Kelen, E. Çubuk Demiralay, S. Şen, and G. Özkan, "Separation of abscisic acid, indole-3-acetic acid, gibberellic acid in 99R (Vitis berlandieri $\times$ Vitis rupestris) and rose oil (Rosa damascena Mill.) by reverse phase liquid chromatography," Turkish Journal of Chemistry, vol. 28, no. 5, pp. 603-610, 2004.

[8] C. L. Patten and B. R. Glick, "Bacterial biosynthesis on indole-3-acetic acid," Canadian Journal of Microbiology, vol. 42, no. 3, pp. 207-220, 1996.

[9] F. Ahmad, I. Ahmad, and M. S. Khan, "Indole acetic acid production by indigenous isolates of Azotobacter and fluorescent Pseudomonas in the presence and absence of tryptophan," Turkish Journal of Biology, vol. 29, pp. 29-34, 2005. 